\title{
Effect of water on elastic and creep properties of self-standing clay films
}

Benoit Carrier, ${ }^{\dagger}$ Matthieu Vandamme, ${ }^{*, \dagger}$ Roland J.-M. Pellenq, ${ }^{\ddagger}, \boldsymbol{\Phi}, \S$ Michel Bornert, $^{\dagger}$ Eric Ferrage, $\|$ Fabien Hubert, $\|$ and Henri Van Damme ${ }^{\ddagger}, \boldsymbol{\Phi}, \S$

†Université Paris-Est, Laboratoire Navier (UMR 8205), CNRS, ENPC, IFSTTAR, F-77455 Marne-la-Vallée, France.

$\ddagger$ Department of Civil and Environmental Engineering, Massachusetts Institute of Technology, 77 Massachusetts Avenue, Cambridge, Massachusetts 02139, United States. \Centre Interdisciplinaire des Nanosciences de Marseille, CNRS (UPR 7251), Campus de Luminy, 13288 Marseille Cedex 09, France.

$\S<M S E>2$, UMI 3466, CNRS-MIT, 77 Massachusetts Avenue, Cambridge, Massachusetts 02139, United States.

|| Université de Poitiers/CNRS, UMR 7285 IC2MP, 86022 Poitiers, France.

E-mail: matthieu.vandamme@enpc.fr

\begin{abstract}
We characterized experimentally the elastic and creep properties of thin self-standing clay films, and how their mechanical properties evolved with relative humidity and water content. The films were films of clay montmorillonite $\mathrm{SWy}-2$, obtained by evaporation of a clay suspension. Three types of films were manufactured, which differed by their interlayer cation: sodium, calcium, or a mixture of sodium with calcium. The orientational order of the films was characterized by X-ray diffractometry. The films were mechanically solicited in tension, the resulting strains being measured by Digital
\end{abstract}


Image Correlation. We measured the Young's modulus and the creep over a variety of relative humidities, on a full cycle of adsorption-desorption for what concerns the Young's modulus. Increasing relative humidity made the films less stiff and made them creep more. Both the elastic and creep properties depended significantly on the interlayer cation. For the Young's modulus, this dependence must originate from a scale greater than the scale of the clay layer. Also, hysteresis disappeared when plotting the Young's modulus vs. water content instead of relative humidity. Independent of interlayer cation and of relative humidity greater than $60 \%$, after a transient period, the creep of the films was always a logarithmic function of time. The experimental data gathered on these mesoscale systems can be of value for modelers that aim at predicting the mechanical behavior of clay-based materials (e.g., shales) at the engineering macroscopic scale from the one at the atomistic scale, for them to validate the first steps of their upscaling scheme. They provide also valuable reference data for bioinspired clay-based hybrid materials.

\section{Introduction}

Understanding the short and long-term mechanical behavior of clay-based materials and the sensitivity of this behavior to water is relevant for a variety of applications. For instance, a deep disposal facility for high-level and intermediate-level long-lived nuclear waste is being developed in France, in a clayey sedimentary rock called argillite: ${ }^{1}$ after a few hundred years, confinement of the radionuclides must be ensured by the geological barrier for more than 100,000 years, during which the mechanical integrity of the barrier needs to be guaranteed, in spite of the expected variations of thermal and hygric conditions. Also, the stability of slopes — and therefore the risk of landslides - is governed not only by the short-term mechanical behavior of soils, but by their long-term behavior as well. ${ }^{2}$ Finally, a better understanding of the mechanical behavior of shales - a heterogeneous rock that often contains clay - is of value not only to optimize the process of hydraulic fracturing used in the shale gas industry, 
but also to ensure the stability of boreholes in conventional oil and gas reservoirs, for which the sealing formation is often made of shales. ${ }^{3}$

Macroscopically, some clays expand significantly with water, ${ }^{4}$ partly as a consequence of the swelling of the slit-shaped or lens-shaped void space between the individual clay layers or between stacks of clay layers. ${ }^{5}$ Also, the macroscopic mechanical properties of clay-based materials are known to be sensitive to relative humidity. For instance, uniaxial compression experiments on argillite $^{6-8}$ show that their Young's modulus and strength depend significantly on the water content. Equivalent trends are observed when the elastic properties are measured by nanoindentation. ${ }^{9}$ The creep properties of clay materials are also sensitive to water: the coefficient of secondary consolidation (which characterizes the long-term creep of soils in general) depends on the water content. ${ }^{10}$

The sensitivity to water of macroscopic clay materials stems from the sensitivity to water of the individual clay layer itself. Several recent studies aim at better characterizing and modeling the response of clay-based materials under hydromechanical loading through socalled bottom-up (or upscaling) approaches, in which the goal is to predict the macroscopic behavior by starting from the microscopic level of the clay layer ${ }^{7,11}$. However, the hydromechanical behavior at the scale of the clay layer and the relationship between the behavior of the layer and that of the upper scales need to be better characterized. Moreover, the gap between the scale of the clay layer and the macroscopic scale is huge, which makes the elaboration and the validation of upscaling schemes more difficult.

Here, we propose and manufacture clay materials at a scale that is intermediate between the scale of the clay layer and the scale of macroscopic natural clay-based materials. The materials we design are self-standing films of pure clay with a thickness of a few dozen micrometers, which are much larger than individual clay layers (whose thickness is on the order of the nanometer) and can be probed mechanically, but remain much smaller and much simpler than macroscopic natural clay-based materials. For instance, we showed in a previous work that the swelling of those films with variations of relative humidity can be easily 
inferred from the swelling of the slit-shaped void space between the individual clay layers (i.e., the so-called interlayer space). ${ }^{12}$ Here, we characterize the orientational order and the mechanical properties of those films, which can be of value for instance for modelers aiming at validating the first steps of their upscaling scheme. The idea of manufacturing such films and characterizing their mechanical properties is readily inspired from the work of Zabat et al. which, to our best knowledge, is the first textural and mechanical study of self-standing clay films. ${ }^{13,14}$ Actually, self-standing clay films with good transparency have been manufactured and used for several decades for spectroscopic (UV-Visible, IR, fluorescence) and structural (X-ray) studies of clay-organic intercalates, including their sensitivity to water. ${ }^{15-17}$ Claybased films have also been investigated as mimics of nacre ${ }^{18-20}$.

In the present work, we prepared thin films of montmorillonite, on which we performed tensile tests in order to characterize an elastic property (i.e., the Young's modulus) and a viscous property (i.e., creep). In order to assess the effect of water, the tensile tests were performed over a wide range of relative humidities. Since the mechanical behavior of clays and their sensitivity to water depend on the interlayer cation, we manufactured films from montmorillonites with various interlayer cations: sodium, calcium, and a mixture of sodium with calcium. First, we present the materials and methods. Then, we introduce the results and discuss them.

\section{Materials and methods}

\section{Materials}

We prepared materials from a natural montmorillonite SWy-2 purchased from the Source Clay Repository of the Clay Mineral Society. SWy-2 is a low-charge Wyoming montmorillonite, whose structural formula is $\left(\mathrm{Al}_{3.23} \mathrm{Mg}_{0.56} \mathrm{Fe}_{0.42}\right)\left(\mathrm{Si}_{7.89} \mathrm{Al}_{0.11}\right) \mathrm{O}_{20}(\mathrm{OH})_{4}\left(\mathrm{Ca}_{0.16} \mathrm{Na}_{0.36^{-}}\right.$ $\left.\mathrm{K}_{0.03}\right)^{21}$ : naturally, the clay SWy-2 contains both sodium and calcium interlayer cations, in a ratio of about 2 to 1 . Only the clay fraction with particles smaller than $2 \mu \mathrm{m}$ was conserved, 
following the process described by Arroyo et al. ${ }^{22}$ The material was then homoionized with either sodium cations or calcium cations. Thus, we obtained three types of montmorillonite which differed by their interlayer cation, from which we prepared three types of clay films: films from the natural SWy-2 clay (which contained both sodium and calcium interlayer cations, and were coined 'raw-SWy-2'), films from the SWy-2 clay homoionized with sodium (which were coined ' $\mathrm{Na}^{+}-\mathrm{SWy}-2$ '), and films from the SWy-2 clay homoionized with calcium (which were coined ' $\mathrm{Ca}^{2+}-\mathrm{SWy}-2$ '). The films were manufactured by evaporation of a clay suspension. The thickness of the prepared films was a few dozens of microns. The methods to homoionize the raw material and to prepare the clay films are described in detail elsewhere. ${ }^{12}$ SEM pictures of the films are given in Fig. 1.

We measured the elastic stiffness of the three types of clay films. We measured the creep properties of the films $\mathrm{Na}^{+}-\mathrm{SWy}-2$ and $\mathrm{Ca}^{2+}{ }_{-} \mathrm{SWy}-2$ only. In order to perform those various measurements, upon application of a mechanical load to the sample, we needed to measure the strain of the sample: those measurements were performed by Digital Image Correlation (DIC), which is introduced later. Note that we also measured elsewhere the adsorption isotherms of the films, ${ }^{12}$ and how the films swelled when relative humidity was varied. ${ }^{12}$ In parallel of the mechanical characterization here performed, we also conducted a characterization of the orientational order of the obtained films, which is the focus of the next section.

\section{Characterization of orientational order of clay films}

We considered the films to be transverse isotropic, with the plane of transverse isotropy being that of the films. ${ }^{23}$ We characterized the orientational order of particles in the obtained films by analyzing experimental rocking curves. The basic principle of this technique is to operate at a fixed $2 \theta$ value, corresponding here to the 001 Bragg reflection of the clay material under investigation, and to rotate the entire system of an angle $\alpha$ with respect to the film orientation. Accordingly, analysis of experimental intensity provides direct information on 


\section{a) raw-SWy-2}

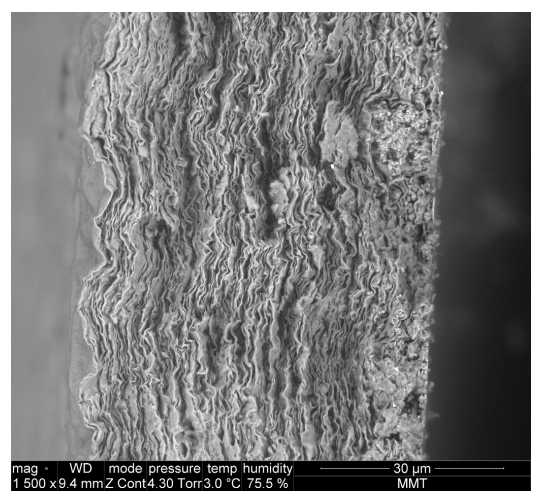

b) $\mathrm{Ca}^{2+}-\mathrm{SWy}-2$

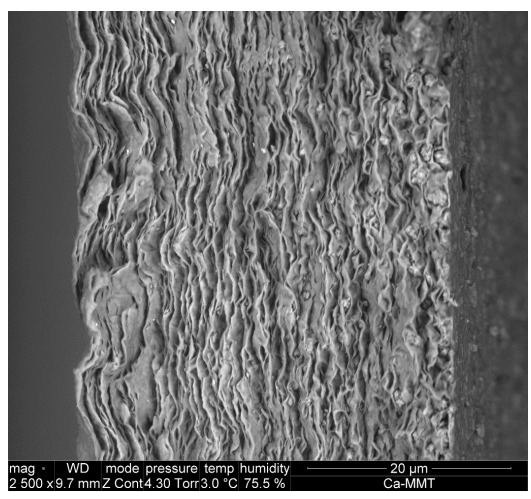

c) $\mathrm{Na}^{+}-\mathrm{SWy}-2$

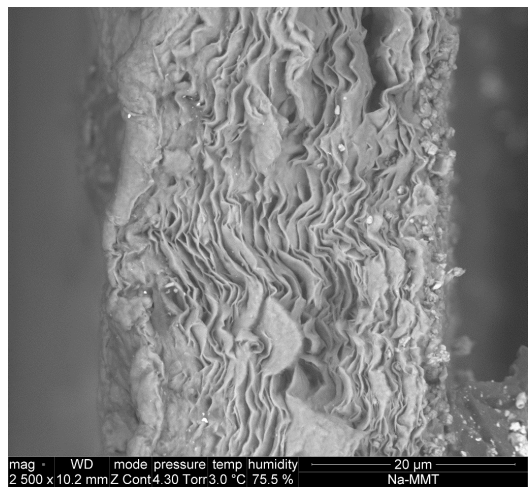

Figure 1: SEM pictures of the edge of the manufactured clay films, at a relative humidity of $75.5 \%$ : a) raw-SWy-2, b) $\mathrm{Ca}^{2+}{ }_{-} \mathrm{SWy}-2$, and c) $\mathrm{Na}^{+}-\mathrm{SWy}-2$. The pictures were acquired by L. Wang at the LMS laboratory at Ecole Polytechnique (Palaiseau, France). 
the proportion of particles forming an angle $\alpha$ with the film geometry. The experimental curves were acquired at ambient temperature $\left(\sim 25^{\circ} \mathrm{C}\right)$ and relative humidity $(\sim 40 \%)$ in transmission conditions on an Empyrean Panalytical X-ray diffractometer equipped with an $\mathrm{X}$ 'Celerator detector operating in receiving slit mode. The step size was 0.15 and $0.5^{\circ} \alpha$ in the $0-7$ and $7-90^{\circ} \alpha$ angular ranges, respectively, with a time per step of $10 \mathrm{~s}$. The angular $\alpha$ range probed in this study for each sample depended on both the position of the 001 reflection of the sample and the relative position of the sample holder with respect to the sample in the fixed $2 \theta$ geometry, the sample holder inducing a shadow for both incident and transmitted X-ray beam.

The experimental rocking curves, and how they were analyzed, ${ }^{23-25}$ are provided in Supporting Information. More information on the overall degree of particle orientation in the different films can be obtained through the calculation of the scalar order parameter $S=<\left(3 \cos ^{2} \alpha\right)-1>/ 2$, where $<X>$ holds for the ensemble average of the volumetric quantity $X .{ }^{26}$ This order parameter $S$ can range from $S=0$ for an isotropic medium to $S=1$ for a perfectly anisotropic medium (i.e., with all particles oriented perfectly parallel in the film). The order parameter $S$ of the films raw-SWy-2, $\mathrm{Ca}^{2+}{ }_{-} \mathrm{SWy}-2$, and $\mathrm{Na}^{+}-\mathrm{SWy}-2$ was $0.69,0.79$, and 0.66 , respectively. From those relatively high values, we infer that the clay particles exhibited a preferential orientation in the clay film, as supported by direct observation (see Fig. 1). Also, as suggested by this same direct observation, values of the order parameter $S$ confirm that the $\mathrm{Na}^{+}-\mathrm{SWy}-2$ film and the raw-SWy-2 film were less ordered than the $\mathrm{Ca}^{2+}-\mathrm{SWy}-2$ film.

\section{Measurement of strain by DIC}

We measured the elastic stiffness of the three types of clay films, but the creep properties of the films $\mathrm{Na}^{+}{ }_{-} \mathrm{SWy}-2$ and $\mathrm{Ca}^{2+}{ }_{-} \mathrm{SWy}-2$ only. In order to perform those various measurements, upon application of a mechanical load to the sample, the strains were characterized by using digital image correlation (DIC), which is a contact-free technique. ${ }^{27}$ DIC consists in 
acquiring images of the surface of the sample with a digital camera at various times during the experiment. Then, each image is compared with an image of the surface of the sample in its state of reference (i.e., here, before any load was applied to the sample). Points chosen in the reference image are identified in the image of the deformed sample by matching the gray levels: thus, at a given time, the displacement of various points at the surface of the sample is measured. The two-dimensional strain of the observed surface is obtained by spatial differentiation of the displacements, and average strains over regions of interest are obtained from contour integrals. ${ }^{6}$

To take images of the samples during the tests, a Pike camera from Allied Vision Technology was used. The CCD sensor was $2048 \times 2048$-pixels-wide with pixels with a width of $7.4 \mu \mathrm{m}$ and the gray levels were encoded on 8 bits. To improve the contrast of the images, carbon powder was scattered all over the surface of the films. The camera was equipped with optics from Schneider Kreuznach (Apo-Componon $90 \mathrm{~mm}$ lens) with appropriate extension tubes (makro system), so that a pixel in the images represented approximately $25 \mu \mathrm{m}$ (i.e., optical magnification was about 0.3). During experiments at ambient relative humidity, we used another Pike camera (Allied Vision Technology) with a lower resolution: the 2/3-inch CCD sensor was $1388 \times 1038$-pixels-wide with pixels with a width of $5.5 \mu \mathrm{m}$. The images were acquired continuously during the tests at a minimum interval of $250 \mathrm{~ms}$. All images were then analyzed by DIC with the in-house software CMV. ${ }^{6}$ We used 30-pixels-wide correlation windows. First-order affine shape functions were combined with a zero-centered normalized cross-correlation criterion, and subpixel accuracy was obtained by means of a biquintic interpolation of the gray levels. ${ }^{27}$ The physical size of a correlation window was $730 \mu \mathrm{m}$ with the higher resolution camera. With the lower resolution camera, the physical size of the correlation window was $1 \mathrm{~mm}$ (pixel size in the images of about $30 \mu \mathrm{m}$, optical magnification of about 0.18).

We estimated from the analysis of controlled rigid body motions ${ }^{28}$ that the error on the average strain measured by DIC was $6 \times 10^{-5}$, which is small with respect to the magnitude 
of the strains in this study, which were on the order of $10^{-3}$. For a detailed description of how we estimated this error, see the Ph.D. thesis of Carrier. ${ }^{29}$

\section{Method for measurement of Young's modulus}

We aimed at measuring the Young's modulus in the direction parallel to the film. In order to measure this modulus, we performed tensile experiments on the clay films, at various controlled relative humidities. The clay films were stressed in tension in a direction parallel to the films.

First, in each prepared film, samples which were 9.3 -mm-wide and 80-mm-long were cut with sharp blades. The ends of each sample were reinforced with sandpaper before being placed in the grips of the tensile test machine. The free length of the sample was equal to $50 \mathrm{~mm}$. Figure 2 displays the experimental setup.

The tensile tests were carried out under controlled relative humidities in an environmental chamber made of PMMA and built around the testing machine. The relative humidity was controlled with saturated salt solutions. Compressed air was blown into a salt solution so that it reached the desired relative humidity. The humidified air was then injected in the environmental chamber. Thus, the pressure in the chamber was slightly higher than in the room and the relative humidity in the chamber was less sensitive to leaks than if no overpressure had been applied. Equilibration of the chamber required only about 30 minutes. The relative humidity and temperature were recorded continuously with a thermohygrometric sensor. Equilibration of the films with the relative humidity in the environmental chamber required about one hour.

During the tensile tests, we controlled the displacement of the upper grip to perform one or two loading-unloading cycles. A force sensor recorded continuously the force with an accuracy of $1 \mathrm{mN}$. To compute the Young's modulus of the clay films, we used the slope of the unloading portion of the force-strain curve, together with the section of the sample at any relative humidity. To estimate this section, first, we measured the thickness of the samples at 


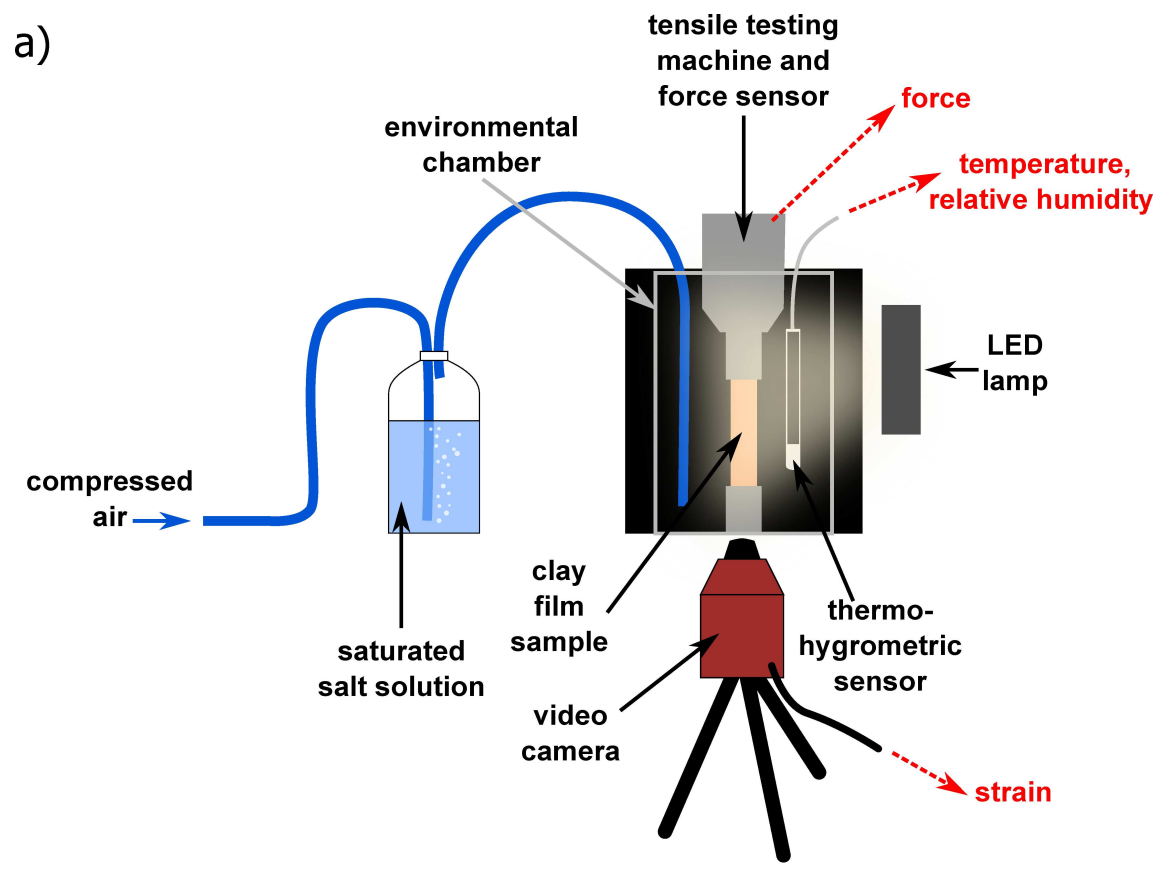

b)
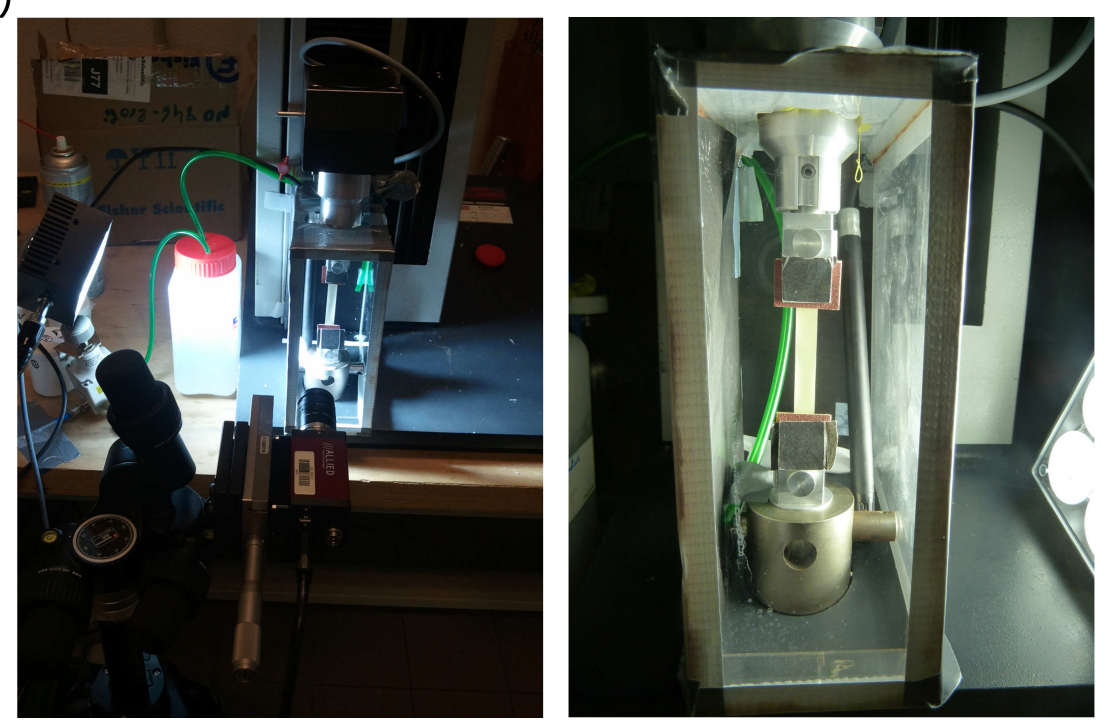

Figure 2: Experimental setup for the measurement of elastic stiffness: a) schematics and b) pictures. 
a reference relative humidity of $35 \%$ with an Environmental Scanning Electron Microscope FEI Quanta 600 available at LMS at École Polytechnique. We estimated the thickness at other relative humidities as follows. First, adsorption isotherms measured elsewhere ${ }^{12}$ made it possible to estimate the water content at a given relative humidity. Second, we estimated the thickness at this water content by considering a linear relationship between thickness and water content, the validity of such linear relation being supported by data gathered by Carrier et al.; ${ }^{12}$ the slope of this linear relation was fitted on this set of data.

A typical stress-strain curve, acquired at ambient conditions (i.e., temperature of about $25^{\circ} \mathrm{C}$ and relative humidity of about $25 \%$ ) is provided as Supporting Information. From this data, we infer that, in all tensile tests performed in this study, for which strains were always smaller than $0.3 \%$, strains were sufficiently small to remain in the linear elastic regime. Also, by loading and unloading 20 times a $\mathrm{Ca}^{2+}{ }_{-} \mathrm{SWy}-2$ film at various displacement rates, ranging from $0.3 \mu \mathrm{m} / \mathrm{s}$ to $32 \mu \mathrm{m} / \mathrm{s}$ (see Supporting Information), we could observe no damage during the successive loading-unloading cycles and we could conclude that the Young's modulus did not depend on the displacement rate. Finally, by performing tensile experiments under ambient conditions on various films made with all materials (see again Supporting Information), we concluded that relative uncertainties on the measured Young's moduli were all smaller than $19 \%$, thus proving that both manufacturing and measurement were repeatable.

\section{Method for measurement of creep property}

We aimed at measuring a creep property of the clay films, i.e., how the clay films deform over time under a constant load. Creep experiments were performed on the films $\mathrm{Ca}^{2+}{ }_{-} \mathrm{SWy}_{-} 2$ and $\mathrm{Na}^{+}-\mathrm{SWy}-2$, whose geometry was the same as for the samples dedicated to the elastic characterization. The free length of the samples was equal to $50 \mathrm{~mm}$.

Figure 3 displays the experimental setup we used to perform creep tests. One end of the sample was placed in a fixed grip and the other end was fixed to a mobile ball slide which 
could move linearly on a rail. The sample was loaded by a weight attached to a string, itself attached to the mobile ball slide. A pulley transformed the vertical gravitational force into a horizontal force on the ball slide. In order to minimize friction, the mobile part had a linearmotion bearing at the contact with a lubricated rail. Before performing any experiment, we calibrated the device: to measure the friction, we loaded the device with various weights. For each weight, we measured the force transmitted by the ball slide with a force sensor having an accuracy of $1 \mathrm{mN}$. We fitted the data with a linear function. The slope of this function was equal to 1 and the extrapolation to a measured force equal to zero gave a friction of $0.11 \pm 0.1 \mathrm{~N}$. In all results presented in this study of the creep properties, every applied force was corrected by taking into account this friction. To be consistent from one sample to another, the load will be expressed in force per clay layer, i.e., the force transmitted to the sample divided by the number of clay layers in the thickness of the sample, which was estimated by dividing the surface density of the dry film by the surface density of a clay layer.

To perform creep tests at various relative humidities, the creep test device was placed in an environmental chamber. The relative humidity was controlled with saturated salt solutions and measured with a hygrometric sensor. Figure 3 shows the experimental setup. Again, the strains of the samples were measured by taking images of the samples and analyzing them with DIC, with the same camera and correlation procedure as the ones presented in Sec. 2.3. Before each creep test, the sample was placed in a chamber in equilibrium with pure water to equilibrate it at a relative humidity close to $100 \%$. Water was then replaced with a saturated salt solution to bring the chamber to the desired relative humidity. The hydric starting points of all creep tests were therefore located on the desorption branch of the adsorption isotherms. 

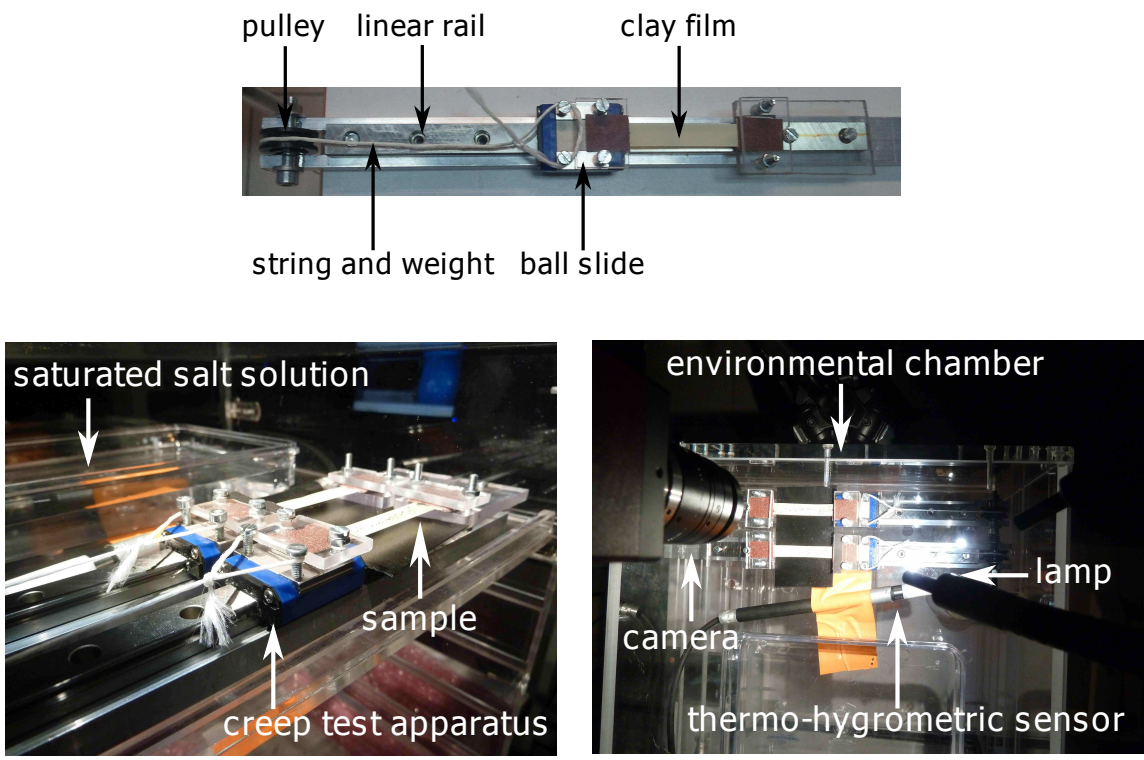

Figure 3: Pictures of the experimental setup to measure tensile creep under controlled relative humidity.

\section{Results and discussion}

\section{Effect of water content on Young's modulus}

Figure 4 displays the Young's modulus of the raw-SWy-2, $\mathrm{Ca}^{2+}{ }_{-} \mathrm{SWy}_{-}$, and $\mathrm{Na}^{+}-\mathrm{SWy}-2$ films versus relative humidity and water content. Several samples of each material were tested: we observed a good reproducibility of the tests. The $\mathrm{Ca}^{2+}-\mathrm{SWy}-2$ film was the stiffest one, with Young's moduli ranging from $2.4 \mathrm{GPa}$ at high water content to $6.2 \mathrm{GPa}$ at low water content, while the Young's moduli of the $\mathrm{Na}^{+}-\mathrm{SWy}-2$ film ranged from $1.0 \mathrm{GPa}$ to 5.6 GPa. The raw-SWy-2 film exhibited an intermediate behavior: at low water content, its Young's modulus was smaller than the one of the $\mathrm{Ca}^{2+}{ }_{-} \mathrm{SWy}-2$ film $(5.6 \mathrm{GPa}$ versus $6.2 \mathrm{GPa}$, respectively); however, at a water content of $0.2 \mathrm{~g} / \mathrm{g}$ of dry clay, its Young's modulus was higher than the one of the $\mathrm{Ca}^{2+}{ }_{-} \mathrm{SWy}-2$ film (3.3 GPa versus 2.8 GPa).

The nature of the cation had a clear impact on the elastic properties of clay films at a given water content. The film made with Ca-exchanged montmorillonite (i.e., the $\mathrm{Ca}^{2+}{ }_{-} \mathrm{SWy}-$ 2 film) was always stiffer than the film made with Na-exchanged montmorillonite (i.e., the $\mathrm{Na}^{+}-\mathrm{SWy}-2$ film). But we also observed an effect of the nature of the cation on the softening 
a)
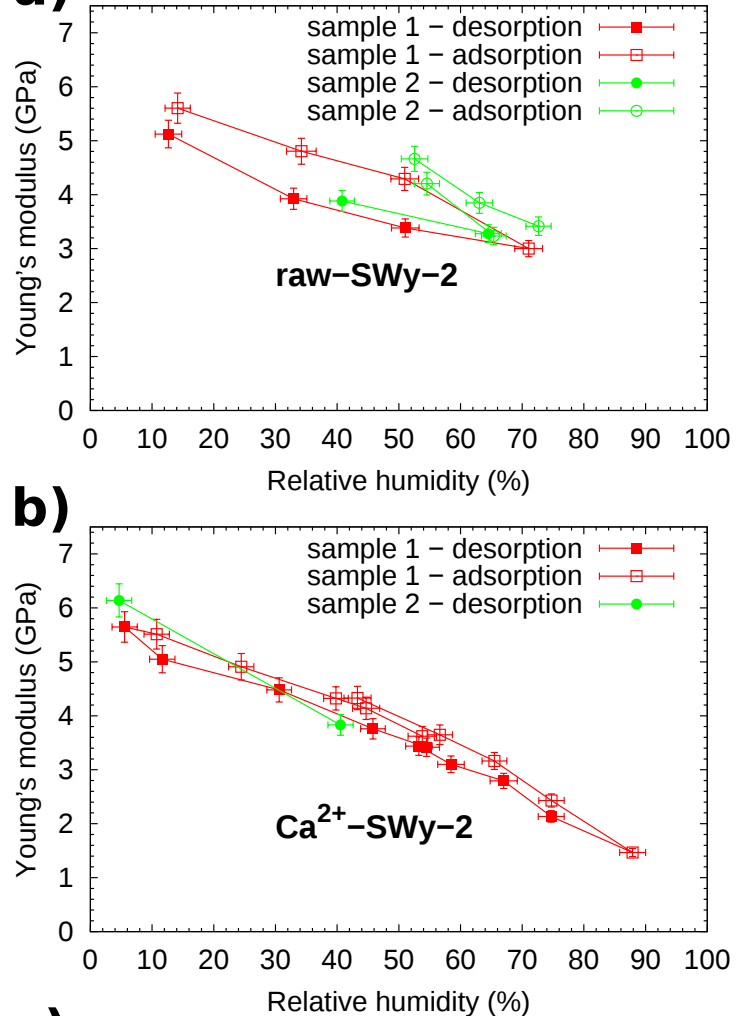

c)

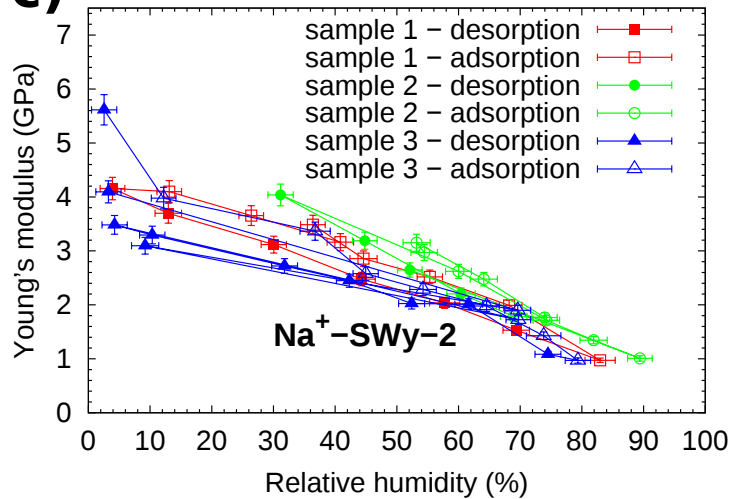

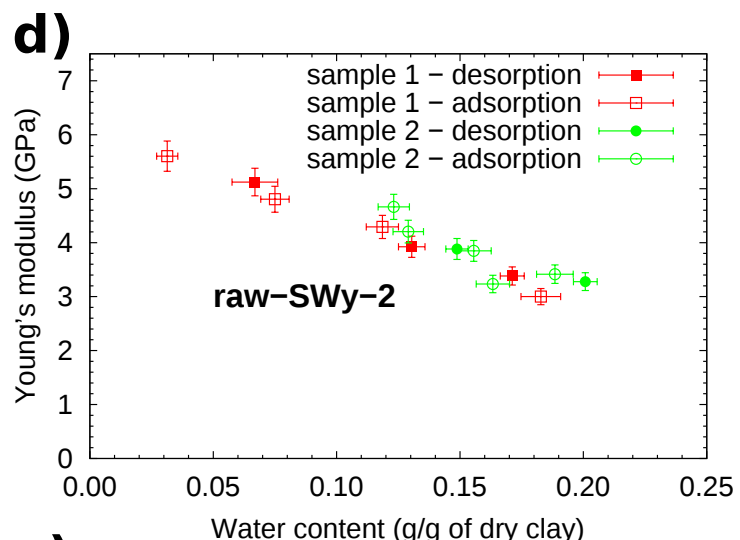

e)

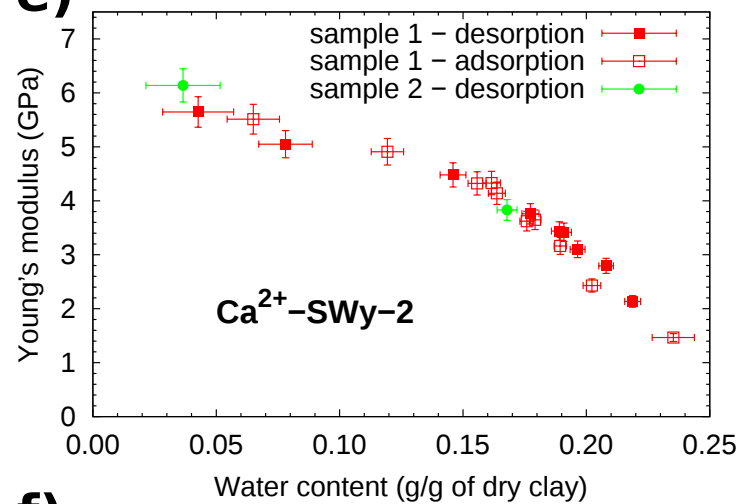

f)

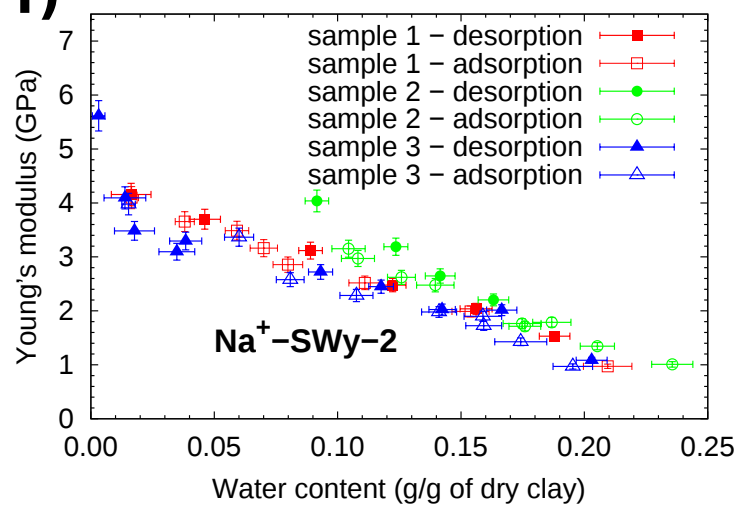

Figure 4: Young's modulus of clay films as a function of relative humidity and water content: (a) and (d) raw-SWy-2-raw, (b) and (e) $\mathrm{Ca}^{2+}{ }_{-} \mathrm{SWy}-2$, (c) and (f) $\mathrm{Na}^{+}-\mathrm{SWy}-2$. For each material, several samples were tested at various relative humidities.

of the films with the increase of water content. Between the smallest and the largest water contents (i.e., about $0.02 \mathrm{~g} / \mathrm{g}$ and $0.24 \mathrm{~g} / \mathrm{g}$, respectively), the ratio of the Young's moduli was equal to approximately 6 for the $\mathrm{Ca}^{2+}{ }_{-} \mathrm{SWy}-2$ films while it was equal to approximately 3 in the case of the $\mathrm{Na}^{+}-\mathrm{SWy}-2$ films. The Young's modulus of the $\mathrm{Ca}^{2+}{ }_{-} \mathrm{SWy}_{-2}$ films was therefore much more sensitive to water than that of the $\mathrm{Na}^{+}-\mathrm{SWy}-2$ films. Again, the films 
made with the natural clay raw-SWy-2 exhibited an intermediate behavior. The difference in sensitivity to the water content, in particular between the $\mathrm{Ca}^{2+}{ }_{-} \mathrm{SWy}-2$ films and the $\mathrm{Na}^{+}-\mathrm{SWy}-2$ films, is quite surprising as, over a full adsorption/desorption cycle, the water contents of the films varied over an identical range.

Part of the decrease of stiffness upon an increase of water content is a geometrical effect consecutive to an increase of basal spacing. ${ }^{30}$ In order to obtain results insensitive to this geometrical effect, we now choose to focus no more on the Young's modulus of the clay films, but on a normalized stiffness. This normalized stiffness was computed as the slope of the force-strain curve divided by an estimate of the number of clay layers in the film, the basal spacing of a dry clay layer (i.e., $9.55 \AA$, which corresponds to about 1050 layers through the thickness of a 1- $\mu$ m-thick film), and the width of the sample. Note that, with this definition, the normalized stiffness can also be said to be equal to the slope of a stress-strain curve, where the stress is calculated by dividing the applied force by the cross-sectional area of the dry film, whatever the hydric conditions of the experiment are. The number of clay layers in the thickness of a film was estimated (see Sec. 2.5) to be approximately equal to 25000, 16000, and 40000 for $\mathrm{Ca}^{2+}{ }_{-} \mathrm{SWy}-2, \mathrm{Na}^{+}-\mathrm{SWy}-2$, and raw-SWy-2, respectively. Figure 5 displays this normalized stiffness upon a full adsorption/desorption cycle for the three types of films tested. As expected, all samples exhibited a softening upon hydration and a stiffening upon dehydration with a hysteresis between the two branches. Moreover, the $\mathrm{Ca}^{2+}{ }_{-} \mathrm{SWy}-2$ and raw-SWy-2 films were stiffer than the $\mathrm{Na}^{+}{ }_{-} \mathrm{SWy}-2$ film, all the more so as the relative humidity was low.

As can be observed in Figs. 4 and 5, the dependence of the Young's modulus on the relative humidity exhibited a significant hysteresis for the raw-SWy-2 samples, but no hysteresis for the $\mathrm{Ca}^{2+}{ }_{-} \mathrm{SWy}-2$ films. Interestingly, the same figures show that, when plotting the Young's modulus versus the water content, this hysteresis almost fully disappeared for all samples. Therefore, upon a cycle of adsorption/desorption, the hysteresis observed on the Young's modulus is mostly due to the fact that water is adsorbed in a hysteretic man- 


\section{a)}
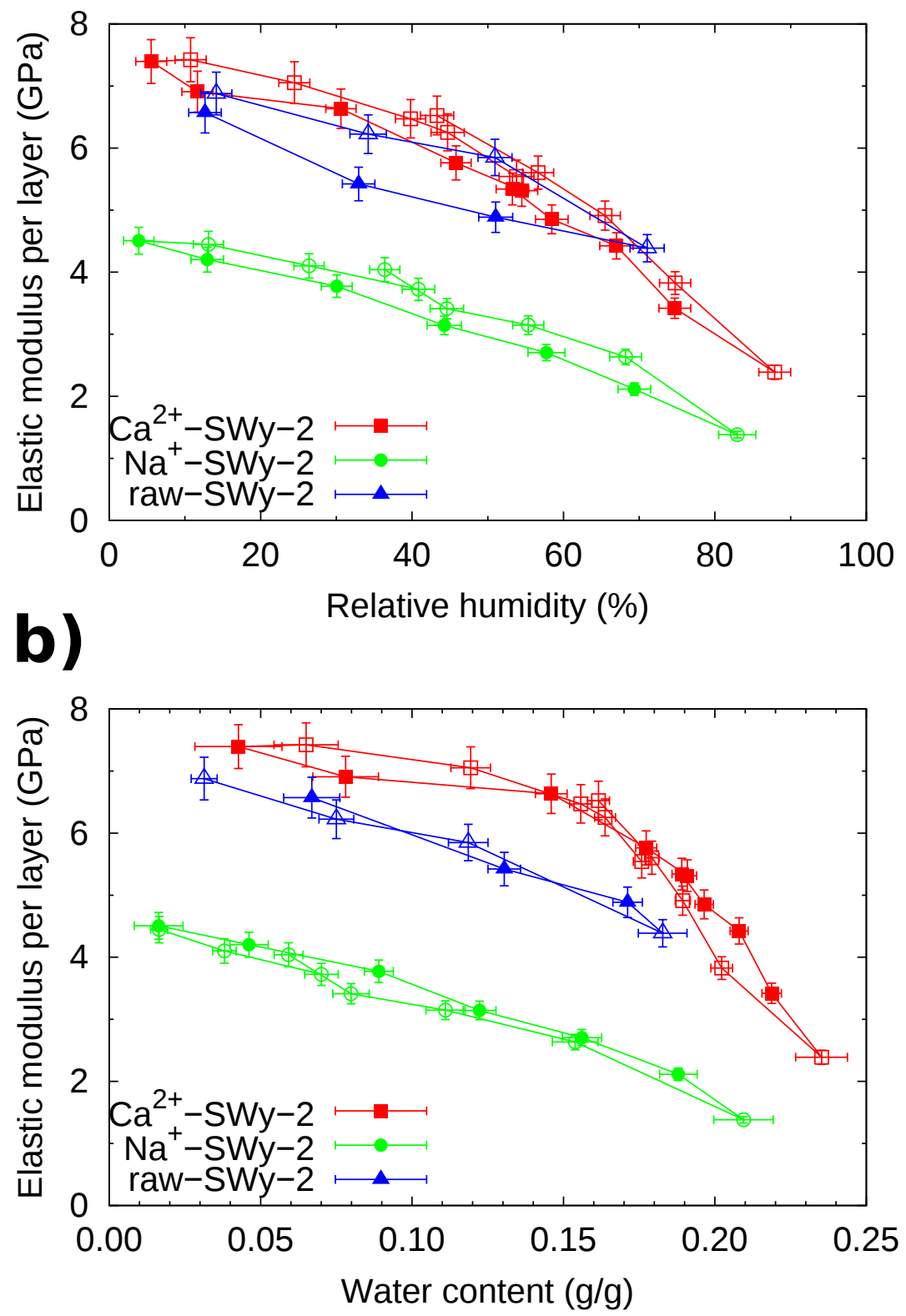

Figure 5: Normalized stiffness of films $\mathrm{Ca}^{2+}{ }_{-} \mathrm{SWy}-2, \mathrm{Na}^{+}-\mathrm{SWy}-2$, and raw-SWy-2, as a function of (a) relative humidity and (b) water content. Hollow and filled symbols correspond to the adsorption and desorption branches, respectively.

ner: in particular, the film on which no hysteresis was observed for the elastic properties (i.e., the $\mathrm{Ca}^{2+}{ }_{-} \mathrm{SWy}-2$ film) is indeed the film on which no hysteresis is observed for the adsorption isotherm. ${ }^{12}$ When focusing on the swelling of clay films induced by variations of relative humidity, one also observes that plotting swelling versus relative humidity exhibits 
a hysteresis, but that plotting swelling versus water content exhibits no hysteresis. ${ }^{12}$ Those observations on hysteresis strongly suggest that the natural state variable on which swelling or elastic properties depend is the water content.

\section{Discussion on effect of interlayer cation}

Figure 5 shows that, at a given relative humidity, the normalized stiffness was larger for the $\mathrm{Ca}^{2+}{ }_{-} \mathrm{SWy}-2$ film than for the $\mathrm{Na}^{+}-\mathrm{SWy}-2$ film. Such result can seem somewhat counterintuitive since, at low relative humidities, adsorption isotherms ${ }^{12}$ and X-ray diffraction results $^{31,32}$ show that the water content and the basal spacing are larger for montmorillonite homoionized with calcium than with sodium. Also, the raw-SWy-2 film —although it contains more sodium cations than calcium cations - exhibited a normalized stiffness close to the one of the $\mathrm{Ca}^{2+}-\mathrm{SWy}-2$ film.

The experimental results show that, even at a given water content, the mechanical properties of the clay films depended on the nature of the interlayer cation: at a given water content, the $\mathrm{Ca}^{2+}{ }_{-} \mathrm{SWy}-2$ film was always stiffer than the $\mathrm{Na}^{+}-\mathrm{SWy}-2$ film, while the film made with natural montmorillonite (i.e., the raw-SWy-2 film, which contained both $\mathrm{Na}^{+}$ and $\mathrm{Ca}^{2+}$ cations) exhibited an intermediate behavior. This result is not consistent with the mechanical behavior of the clay layer as evaluated from numerical simulations. Indeed, molecular dynamics computations showed a limited impact of the nature of the interlayer cation on the elastic properties of the layer, except in the driest states: ${ }^{30}$ as soon as the first water layer is formed, no dependence of the coefficients of the stiffness tensors on the interlayer cation is observed. However, the dependence of the elastic properties of clay-based materials on the interlayer cation was also observed by Wang et al., ${ }^{33}$ who measured the elastic properties of epoxy-clay composites, from which they inferred the elastic properties of the clay minerals only, after subtracting the mechanical contribution of the epoxy by using micromechanical relations: their results show that Ca-rich montmorillonites are stiffer than Na-rich montmorillonites. Note however that the water content of their samples was 
not controlled and therefore was very uncertain. To our knowledge, there is no other work available in the literature in which the mechanical properties of a same clay with various interlayer cations are compared.

If the reason for the dependence of the elastic properties of clay-based materials on the nature of the interlayer cations cannot be found at the scale of the clay layer, it must be found at a scale above. Indeed, the nature of the cation has also an effect on the size and the arrangement of the clay particles and on the mesostructure of the material ${ }^{34,35}$. Experiments show that exfoliating smectite layers with calcium counterions is very difficult ${ }^{36-38}$ and that Ca-exchanged smectite layers form thicker tactoids in solution than Na-exchanged smectite layers $^{35}$. A microscopic reason for those observations can be that cohesive forces between neighboring layers depends on the counterion. ${ }^{29}$ Indeed, the cohesion of clay systems is mainly governed by electrostatic interactions (rather than by Van der Waals ones), so that it is in particular sensitive to the valence of the counterion. Note that cohesion can vary even if stiffness does not, so that the fact that Ca-rich clays are more cohesive than Na-rich clays is not inconsistent with the molecular simulations of Carrier et al., ${ }^{30}$ which show that, at a given water content, the counterion has no effect on the stiffness of the stack of clay layers.

In addition, our X-ray diffraction measurements show that the order parameter $S$ is larger in the Ca-exchanged than in the Na-exchanged sample, showing that the orientational order is better in the former case. One can expect that the elastic properties of the film depend on this orientational order since the stiffness coefficients of clay particle that are solicited by tensile loading of the film depend on the orientation of the particle with respect to the film. Another microstructural feature that could play a role in the mechanical properties of the film is how the contacts between neighboring clay particles are spatially organized, as these contacts govern how stresses are being transmitted throughout the film. Intuitively, one could expect that a larger average area of contact would translate into a greater stiffness. It may be that, in our self-standing films, the average area of contact between clay particles in Ca-exchanged montmorillonite differs from that in Na-exchanged montmorillonite: as a result, for the same 
uniaxial force applied to the film, the stresses (and in particular the shear stresses) acting at the scale of the clay particle would depend on the interlayer cation. Such mesostructural difference could explain our experimental observation that Ca-exchanged films were stiffer than Na-exchanged films. In short, the macroscopic hydromechanical behavior of clays depends strongly on the structure at scales larger than the scale of the clay layer and on the orientational order. This mesostructure should be taken into account in a realistic model to obtain a good estimate of the Young's modulus of an ensemble of particles, may it be ordered or not.

\section{Effect of water on creep property}

The results presented in this section were obtained with the experimental setup displayed in Fig. 3 according to the protocol described in Sec. 2.5. Figure 6(a) displays the typical deformations of a clay film with time. At $\mathrm{t}=0 \mathrm{~s}$, a load equal to $26.1 \mu \mathrm{N}$ per clay layer was applied and was kept constant during the test. The samples exhibited an instantaneous elastic deformation. The creep strain was then calculated as the difference between the total strain and this instantaneous elastic deformation: thus, the creep strain was the delayed part of the deformation. In Fig. 6(a), the creep strain of two $\mathrm{Ca}^{2+}{ }_{-} \mathrm{SWy}-2$ films is displayed in function of time, on a logarithmic scale. After 500 to $600 \mathrm{~s}$, the deformation was a logarithmic function of time. Actually, such feature of a creep strain that evolves linearly with the logarithm of time after a transient period was observed for all films. By analogy with what is done in soil mechanics ${ }^{39}$ we introduce a creep coefficient $\alpha$ defined as the slope of the creep strain versus logarithm of time curve:

$$
\alpha=\frac{d \epsilon}{d(\ln t)} .
$$

For each tensile creep experiment, this creep coefficient was back-calculated from the data acquired once the non-logarithmic transient period is exhausted. 
In Fig. 6(a), tests performed on two $\mathrm{Ca}^{2+}-\mathrm{SWy}-2$ films are displayed: the first one was performed at a relative humidity of $92.0 \pm 2.9 \%$ and the second one at a relative humidity of $77.7 \pm 2.0 \%$. The test at $92.0 \%$ was stopped when the sample failed, while we stopped the test at $77.7 \%$ before failure. Relative humidity had a very clear impact on the creep rate. The creep strain was a linear function of the logarithm of time for both tests and the slope $\alpha$ of this function (which we named creep coefficient) was larger at a higher relative humidity: the creep coefficient $\alpha$ was equal to $0.22 \%$ at a relative humidity of $92 \%$ but to $0.05 \%$ at a relative humidity of $78 \%$.

The observed logarithmic feature of creep is reminiscent of the creep of macroscopic claybased materials or of soils, which is also known to evolve logarithmically with time after a transient period. ${ }^{39}$ However, macroscopically, soils are usually tested in compression or in shear, not in tension. The fact that, here, a logarithmic creep was also observed in tension makes it possible to discard one possible explanation for the origin of such logarithmic creep, which is the free volume dynamics theory. Free volume dynamics can explain why the density of vibrated columns of granular materials evolve logarithmically with time ${ }^{40,41}$, by stipulating that, when the density of the column increases, the free volume between grains decreases, and hence their ability to move and the creep rate. Such theory has also been proposed to explain why the creep of cementitious materials is a logarithmic function of time in the long term. ${ }^{42}$ But, for what concerns our experiments on clay films, since the applied stresses are tensile, the free volume must increase with time, thus making it impossible to explain why the creep rate would decrease over time. Other potential theories to explain this logarithmic creep, sometimes proposed for other materials that exhibit this same feature (e.g., cement or sand), are, among others: relaxation of internal prestresses, ${ }^{43}$ presence of energy barriers that two solids (e.g., two clay layers) need to overcome in order to slide over each other, ${ }^{44}$ or breakage of bonds or particles. ${ }^{45}$

Figure 6(b) displays the creep strain of two $\mathrm{Na}^{+}-\mathrm{SWy}-2$ films in function of time, on a logarithmic scale. The two tests were performed at the same relative humidity, but at 

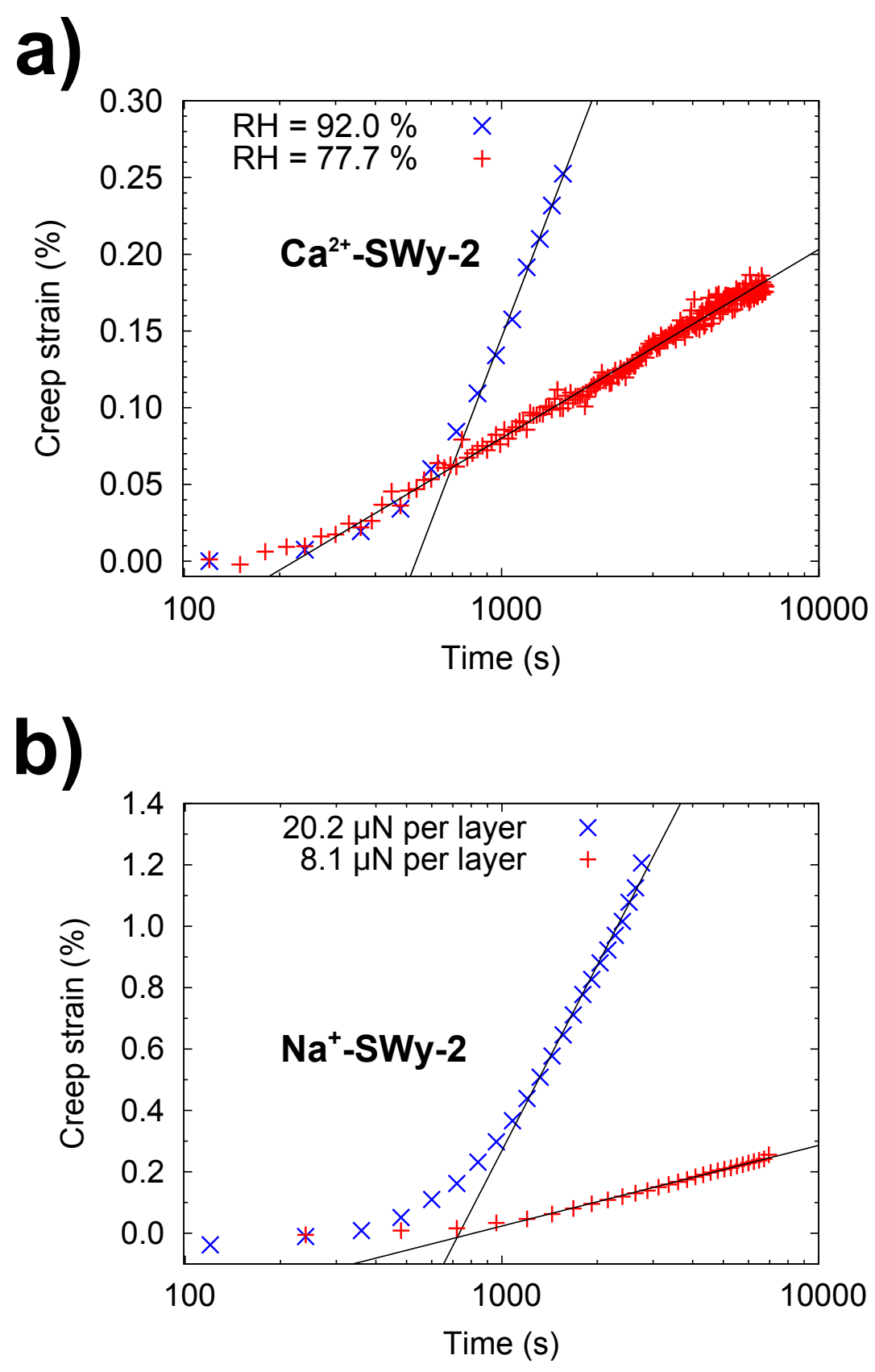

Figure 6: (a) Creep strain of films of $\mathrm{Ca}^{2+}{ }_{-} \mathrm{SWy}-2$ as a function of time (logarithmic scale) at various relative humidities. The force transmitted to the samples was identical for both tests (i.e., $26.1 \mu \mathrm{N}$ per clay layer). (b) Creep strain of $\mathrm{Na}^{+}-\mathrm{SWy}-2$ films as a function of time at various applied forces. The relative humidity was identical for both tests $(\sim 92 \%)$.

various loads (8.1 and $20.2 \mu \mathrm{N}$ per clay layer, respectively). The test with a load equal to $20.2 \mu \mathrm{N}$ per layer was stopped when the sample failed, while we stopped the test with a load of $8.1 \mu \mathrm{N}$ per layer before failure. For both films, after a transient period, the creep strain 
was a logarithmic function of time. The amplitude of the creep increased with load: for a load equal to $8.1 \mu \mathrm{N}$ per clay layer, the creep coefficient $\alpha$ was equal to $0.12 \%$, while this creep coefficient was equal to $0.91 \%$ for a load equal to $20.2 \mu \mathrm{N}$ per layer. Therefore, the amplitude of creep increased faster than the load: when the load was multiplied by 2.5 , the creep coefficient $\alpha$ increased by a factor 4.3. A more thorough study of the effect of the load on the creep coefficient is presented next.

Figure 7 displays the creep coefficient $\alpha$ in function of load for $\mathrm{Ca}^{2+}{ }_{-} \mathrm{SWy}-2$ films and $\mathrm{Na}^{+}{ }_{-}$ SWy-2 films at a given relative humidity. Four sets of data are displayed, which correspond to 2 experiments: a first experiment on two samples cut out from the same $\mathrm{Ca}^{2+}{ }_{-} \mathrm{SWy}-2$ film and on two samples cut out from the same $\mathrm{Na}^{+}{ }_{-} \mathrm{SWy}-2$ film, and a second experiment on a sample cut out from another $\mathrm{Ca}^{2+}{ }_{-} \mathrm{SWy}-2$ film and on a sample cut out from another $\mathrm{Na}^{+}-$ SWy-2 film. In each experiment, all samples were tested at the same time while located in the same environmental chamber. The 2 experiments were performed at different times but with the same environmental chamber. When the films were loaded during the same experiment, for both materials, the creep coefficient was an increasing function of load in a roughly linear manner. However, experiments performed at different times were not consistent with each other. Although the relative humidities measured in the two experiments were close to each other (e.g., $77.5 \pm 2.8 \%$ and $77.7 \pm 2.5 \%$ for the two sets of data on the $\mathrm{Ca}^{2+}{ }_{-} \mathrm{SWy}-2$ films), because of the experimental difficulty in controlling temperature and relative humidity precisely, the uncertainty on the actual local relative humidity with which the films were in equilibrium may be up to $5 \%$. Moreover, at relative humidities around $80 \%$, the creep coefficient $\alpha$ was very sensitive to relative humidity, as is shown next. Such uncertainty could explain the discrepancy between the sets of experiments 1 and 2 displayed in Fig. 7 . In any case, experiments under the very same environmental conditions suggested that the creep coefficient depends on the load and that this dependence is quite linear. Therefore, we introduce the creep compliance $\kappa$ (expressed in $\mathrm{Pa}^{-1}$ ), defined by: 


$$
\kappa=\alpha \frac{b d}{F}
$$

where $F$ is the force applied by clay layer, $b$ is the width of the sample $(b=9.3 \mathrm{~mm}$ for all creep tests), and $d$ is the basal spacing of a dry clayer (i.e., $9.55 \AA$ ). The results of all creep tests, at all relative humidities and for both types of films, are given as Supporting Information.

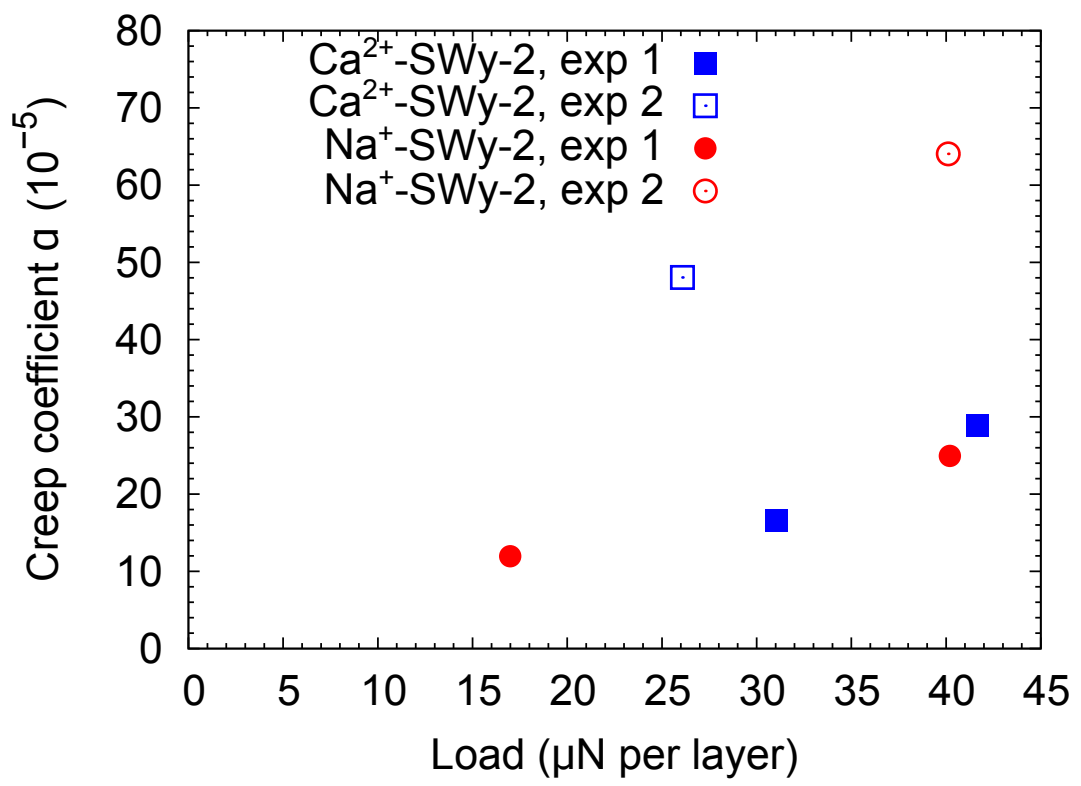

Figure 7: Creep coefficient $\alpha$ as a function of load at a given relative humidity. For each film, exp 1 and exp 2 correspond to two different experiments. During experiment 1, two identical films were loaded at the same time in the same environmental chamber. The relative humidity was equal to $77.5 \pm 2.8 \%$ and $81.3 \pm 1.5 \%$ for $\mathrm{Ca}^{2+}{ }_{-} \mathrm{SWy}_{-} 2$ and $\mathrm{Na}^{+}{ }_{-} \mathrm{SWy}_{-}$, respectively. Experiment 2 was performed on different films, at a different time. The relative humidity was equal to $77.7 \pm 2.5 \%$ and $80.3 \pm 2.3 \%$ for $\mathrm{Ca}^{2+}{ }_{-S W y-2}$ and $\mathrm{Na}^{+}-\mathrm{SWy}_{-} 2$, respectively.

Figure 8 displays the creep compliance $\kappa$ in function of relative humidity for both the $\mathrm{Ca}^{2+}{ }_{-} \mathrm{SWy}_{-} 2$ and $\mathrm{Na}^{+}-\mathrm{SWy}-2$ films. The error bars on the creep compliance are only visible for the data with the lowest creep compliance, which correspond to films that creep the least, and on which the noise on the creep measurement was thus the largest. At a given relative humidity, the creep compliance was much higher for the $\mathrm{Na}^{+}-\mathrm{SWy}-2$ films than for the $\mathrm{Ca}^{2+}{ }_{-} \mathrm{SWy}-2$ films, by about one order of magnitude. Also, for both types of films, we 
observed a tremendous effect of relative humidity on the creep compliance: when increasing the humidity from about $60 \%$ to about $95 \%$, their creep compliance increased by about two orders of magnitude.
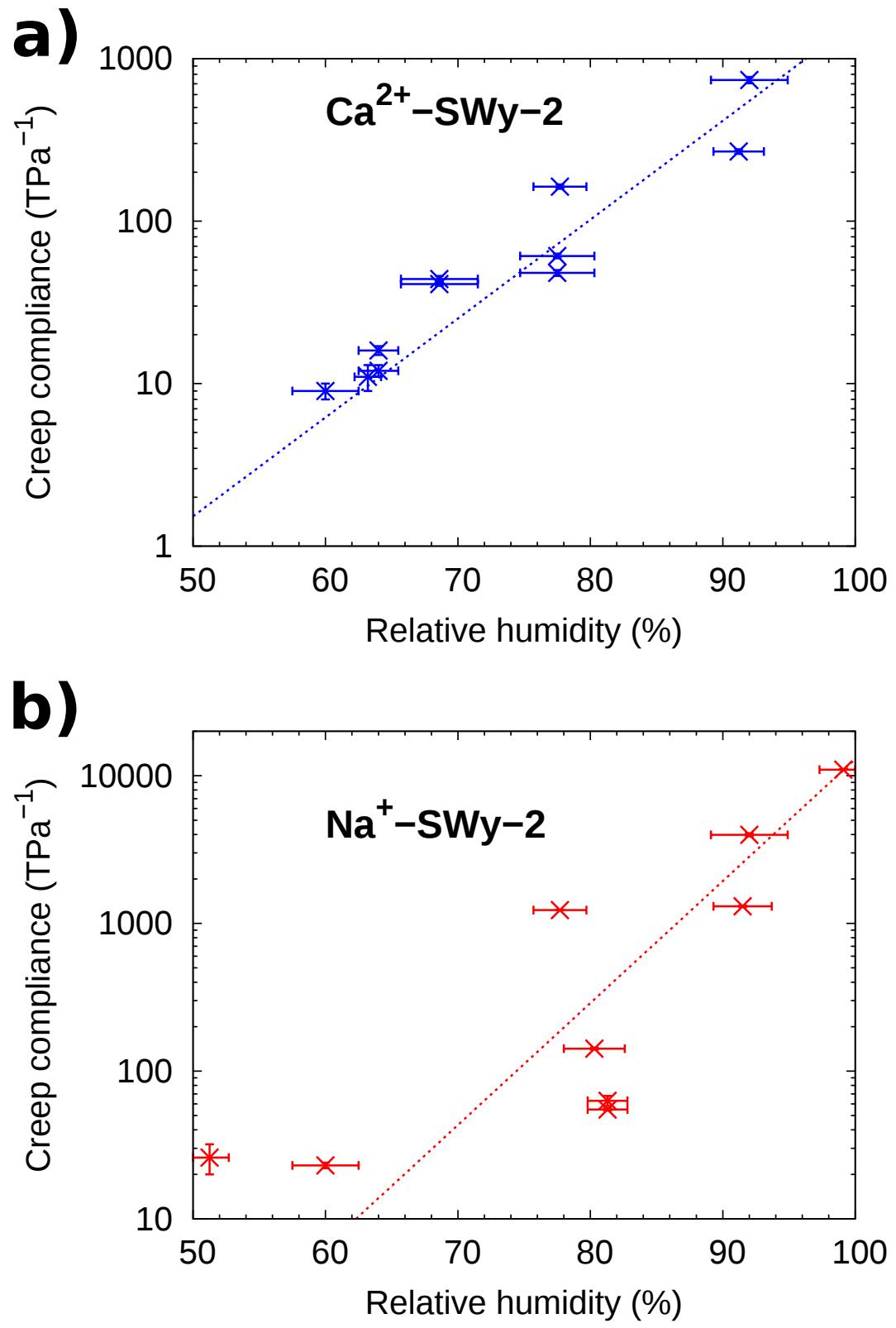

Figure 8: Creep compliance $\kappa$ in function of relative humidity for (a) sample $\mathrm{Ca}^{2+}{ }_{-} \mathrm{SWy}-2$ and (b) $\mathrm{Na}^{+}-\mathrm{SWy}-2$. Dotted lines are visual guides. 
days was impossible: the relative humidity and water content fluctuated slightly over time. The creep was therefore indistinguishable from the slight swelling and shrinkage of the film or the small variations of the elastic properties shown in Fig. 4.

Figure 9 displays the creep compliance as a function of water content. We performed a linear regression of the logarithm of the compliance versus water content (dashed lines in Figure 9) and obtained a correlation coefficient equal to 0.83 for the $\mathrm{Ca}^{2+}{ }_{-} \mathrm{SWy}-2$ films and to 0.78 for the $\mathrm{Na}^{+}-\mathrm{SWy}-2$ films. The compliance can therefore be well approximated by an exponential function of water content: creep is very much sensitive to the water content. The physical mechanism behind this strong dependency remains unclear.

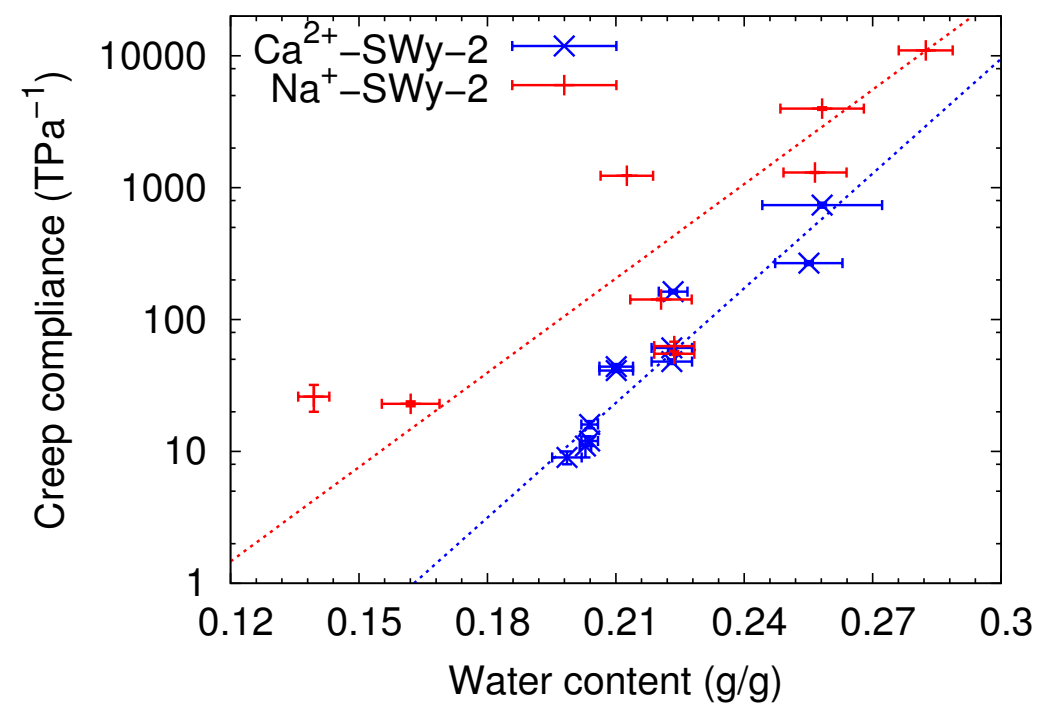

Figure 9: Creep compliance $\kappa$ in function of water content for samples $\mathrm{Ca}^{2+}{ }_{-} \mathrm{SWy}-2$ and $\mathrm{Na}^{+}-\mathrm{SWy}-2$.

\section{Conclusions}

The conclusions of this work are:

- Whatever the interlayer cations are (here, sodium, calcium, or a mixture of sodium with calcium), the elastic and creep properties of clay films depended on relative humidity/water content. Increasing the water content made the clay films less stiff and 
made them creep more.

- The nature of the interlayer cation had a significant effect on the elastic and creep properties of the clay films and on the dependence of these properties on relative humidity. Since the stiffness tensor of a clay layer at a given water content, as evaluated by molecular simulations, does not depend on the nature of the interlayer cation, ${ }^{30}$ the reason why the elastic properties of the films depended on the interlayer cation must originate from a scale greater than the scale of the clay layer: the structure of the films at a mesoscale (e.g., the size and shape of the clay tactoids) must significantly impact the elastic behavior of the film. It is likely that such structure at a mesoscale also impacts the creep behavior of the films and at least partly explains why creep depended on the nature of the interlayer cation.

- The Young's modulus exhibited a clear hysteresis when plotted versus relative humidity, but no hysteresis when plotted versus water content. Therefore, the hysteresis observed when plotting Young's modulus versus relative humidity mostly originates from the hysteresis of the water adsorption isotherm. Such vanishing of hysteresis has also been observed when focusing on the swelling properties of the same clay films. ${ }^{12}$ Therefore, the natural parameter on which elastic and swelling properties of the films depend is the water content, not the relative humidity. Such observation is likely to hold for other mechanical properties and should be recognized by any model of the hydro-mechanical behavior of clay-based materials, at least at the scale of the clay layers or of the clay particles.

- After a transient period, the creep of all tested films was a logarithmic function of time. Since the films were loaded in tension, this logarithmic feature of creep cannot be explained by free volume dynamics. The creep compliance could be well approximated by an exponential function of water content.

In addition to these conclusions, the work here performed provides a complete set of data 
on how the elastic and creep properties of films of montmorillonite with various interlayer cations depend on water content and relative humidity. Moreover, the orientational order of the films was characterized, as well as, elsewhere, their adsorption isotherms and swelling properties. ${ }^{12}$ Such set of data can serve as reference data for scientists working on bioinspired clay-based hybrid materials. It can also be of value for modelers who aim at predicting the mechanical behavior of clay-based materials (e.g., shales) at the macroscopic scale of the engineer, from the behavior at the atomistic scale. Indeed, the results here presented make it possible for them to confront the first steps of their upscaling scheme with experimental data: such confrontation is necessary since, as we observed, the elastic properties of our films depend significantly on the structure at a mesoscale (i.e., at a scale greater than the scale of the clay layer). In particular, the dependence of the Young's modulus on the interlayer cation must originate from this mesoscale. One can reasonably extrapolate that the mesoscale structure is likely to play a significant role not only on the elastic properties of the pure clay films here tested, but on the mechanical properties of all clay-based materials in general.

\section{Acknowledgement}

The authors would like to thank Dr. Sandrine Arrii-Clacens for her help in the Rocking curve acquisition. This work was financially supported by the French Federative Project 'NEEDS

Milieux Poreux' (Great Interdisciplinary Challenge for Nuclear, Energy, Environment, Waste and Society), co-funded by CNRS, Andra, IRSN, EDF and BRGM.

\section{References}

(1) Andra, Evaluation of the feasability of a geological repository in an argillaceous formation; 2005.

(2) USGS, Landslide types and processes; 2004. 
(3) Anderson, R. L.; Ratcliffe, I.; Greenwell, H. C.; Williams, P. A.; Cliffe, S.; Coveney, P. V. Clay swelling - A challenge in the oilfield. 2010.

(4) Delage, P.; Howat, M. D.; Cui, Y. J. The relationship between suction and swelling properties in a heavily compacted unsaturated clay. Engineering Geology 1998, 50, $31-48$.

(5) Mooney, R. W.; Keenan, a. G.; Wood, L. a. Adsorption of water vapor by montmorillonite. II. Effect of exchangeable ions and lattice swelling as measured by x-ray diffraction. J. Am. Chem. Soc. FIELD Full Journal Title:Journal of the American Chemical Society 1952, 74, 1371-1374.

(6) Bornert, M.; Valès, F.; Gharbi, H.; Nguyen Minh, D. Multiscale full-field strain measurements for micromechanical investigations of the hydromechanical behaviour of clayey rocks. Strain 2010, 46, 33-46.

(7) Cariou, S.; Duan, Z.; Davy, C.; Skoczylas, F.; Dormieux, L. Poromechanics of partially saturated COx argillite. Applied Clay Science 2012, 56, 36-47.

(8) Pham, Q. T.; Vales, F.; Malinsky, L.; Nguyen Minh, D.; Gharbi, H. Effects of desaturation-resaturation on mudstone. Physics and Chemistry of the Earth 2007, 32, 646-655.

(9) Magnenet, V.; Giraud, A.; Auvray, C. About the effect of relative humidity on the indentation response of Meuse/Haute-Marne argillite. Acta Geotechnica 2011, 6, 155166.

(10) Mesri, G. Coefficient of secondary compression. Journal of the Soil Mechanics and Foundations Division 1973, 99, 123-137.

(11) Ortega, J. A.; Ulm, F.-J.; Abousleiman, Y. N. The effect of the nanogranular nature of shale on their poroelastic behavior. Acta Geotechnica 2007, 2, 155-182. 
(12) Carrier, B.; Wang, L.; Vandamme, M.; Pellenq, R. J.-M.; Bornert, M.; Tanguy, A.; Van Damme, H. ESEM study of the humidity-induced swelling of clay film. Langmuir: the ACS journal of surfaces and colloids 2013, 29, 12823-33.

(13) Zabat, M. Microtexture et propriétés mécanique de films solides de particules colloïdales. Ph.D. thesis, Université d'Orléans, 1996.

(14) Zabat, M.; Vayer-Besançon, M.; Harba, R.; Bonnamy, S.; Van Damme, H. Surface topography and mechanical properties of smectite films. Progress in Colloid $\& 3$ Polymer Science 1997, 105, 96-102.

(15) Hauser, E. A.; Le Beau, D. S. Studies on gelation and film formation of colloidal clays. I. The Journal of Physical Chemistry 1938, 42, 961-969.

(16) Serratosa, J. M. Dehydration and rehydration studies of clay minerals by infrared absorption spectra. Clays and Clay Minerals: Proceedings of the Ninth National Conference on Clays and Clay Minerals. 1960; pp 412-418.

(17) Krenske, D.; Abdo, S.; Van Damme, H.; Cruz, M.; Fripiat, J. J. Photochemical and photocatalytic properties of adsorbed organometallic compounds. 1. Luminescence quenching of tris(2,2'-bipyridine)ruthenium(II) and chromium(III) in clay membranes. The Journal of Physical Chemistry 1980, 84, 2447-2457.

(18) Wang, J.; Cheng, Q.; Tang, Z. Layered nanocomposites inspired by the structure and mechanical properties of nacre. Chemical Society Reviews 2012, 41, 1111-1129.

(19) Das, P.; Malho, J.-M.; Rahimi, K.; Schacher, F. H.; Wang, B.; Demco, D. E.; Walther, A. Nacre-mimetics with synthetic nanoclays up to ultrahigh aspect ratios. Nature Communications 2015, 6, 5967.

(20) Bennadji-Gridi, F.; Smith, A.; Bonnet, J. P. Montmorillonite based artificial nacre pre- 
pared via a drying process. Materials Science and Engineering B: Solid-State Materials for Advanced Technology 2006, 130, 132-136.

(21) Mermut, A. R.; Cano, A. F. Baseline studies of the clay minerals society source clays: chemical analyses of major elements. Clays and Clay Minerals 2001, 49, 381-386.

(22) Arroyo, L. J.; Li, H.; Teppen, B. J.; Boyd, S. A. A simple method for partial purification of reference clays. Clays and Clay Minerals 2005, 53, 511-519.

(23) Hubert, F.; Bihannic, I.; Prêt, D.; Tertre, E.; Nauleau, B.; Pelletier, M.; Demé, B.; Ferrage, E. Investigating the anisotropic features of particle orientation in synthetic swelling clay porous media. Clays and Clay Minerals 2013, 61, 397-415.

(24) Cebula, D. J.; Thomas, R. K.; Middleton, S.; Ottewill, R. H.; White, J. W. Neutron diffraction from clay-water systems. Clays and Clay Minerals 1979, 27, 39-52.

(25) Hall, P. L.; Harrison, R.; Hayes, M. H. B.; Tuck, J. J.; Ross, D. K. Particle orientation distributions and stacking arrangements in size-fractionated montmorillonite measured by neutron and X-ray diffraction. Journal of the Chemical Society, Faraday Transactions 1 1983, 79, 1687-1700.

(26) Perdigon-Aller, A. C.; Aston, M.; Clarke, S. M. Preferred orientation in filtercakes of kaolinite. Journal of Colloid and Interface Science 2005, 290, 155-165.

(27) Bornert, M.; Brémand, F.; Doumalin, P.; Dupré, J. C.; Fazzini, M.; Grédiac, M.; Hild, F.; Mistou, S.; Molimard, J.; Orteu, J. J.; Robert, L.; Surrel, Y.; Vacher, P.; Wattrisse, B. Assessment of digital image correlation measurement errors: Methodology and results. Experimental Mechanics 2009, 49, 353-370.

(28) Dautriat, J.; Bornert, M.; Gland, N.; Dimanov, A.; Raphanel, J. Localized deformation induced by heterogeneities in porous carbonate analysed by multi-scale digital image correlation. Tectonophysics 2011, 503, 100-116. 
(29) Carrier, B. Effet de l'eau sur les propriétés mécaniques à court et long termes des argiles gonflantes : expériences sur films autoporteurs et simulations moléculaires. Ph.D. thesis, Université Paris-Est, 2013.

(30) Carrier, B.; Vandamme, M.; Pellenq, R. J.-M.; Van Damme, H. Elastic properties of swelling clay particles at finite temperature upon hydration. The Journal of Physical Chemistry C 2014, 118, 8933-8943.

(31) Bérend, I.; Cases, J.-M.; François, M.; Uriot, J.-P.; Michot, L.; Masion, A.; Thomas, F. Mechanism of adsorption and desorption of water vapor by homoionic montmorillonites: 2. The $\mathrm{Li}+, \mathrm{Na}+, \mathrm{K}+, \mathrm{Rb}+$ and $\mathrm{Cs}+$-echanged forms. Clays and Clay Minerals 1995, 43, 324-336.

(32) Cases, J. M.; Bérend, I.; François, M.; Uriot, J. P.; Michot, L. J.; Thomas, F. Mechanism of adsorption and desorption of water vapor by homoionic montmorillonite; 3, The Mg (super 2+), Ca (super 2+), and Ba (super 3+) exchanged forms. Clays and Clay Minerals 1997, 45, 8-22.

(33) Wang, Z. Z.; Wang, H.; Cates, M. E. Effective elastic properties of solid clays. Geophysics 2001, 66, 428-440.

(34) Shomer, I.; Mingelgrin, U. Direct procedure for determining the number of plates in tactoids of smectites: the Na/Ca-montmorillonite case. Clays and Clay Minerals 1978, 26, 135-138.

(35) Schramm, L. L.; Kwak, J. C. T. Influence of exchangeable cation composition on the size and shape of montmorillonite particles in dilute suspension. Clays and Clay Minerals 1982, 30, 40-48.

(36) Segad, M.; Jönsson, B.; Åkesson, T.; Cabane, B. Ca/Na montmorillonite: Structure, forces and swelling properties. Langmuir 2010, 26, 5782-5790. 
(37) Segad, M.; Hanski, S.; Olsson, U.; Ruokolainen, J.; Åkesson, T.; Jönsson, B. Microstructural and swelling properties of $\mathrm{Ca}$ and $\mathrm{Na}$ Montmorillonite: (In situ) observations with Cryo-TEM and SAXS. Journal of Physical Chemistry C 2012, 116, 7596-7601.

(38) Segad, M.; Jönsson, B.; Cabane, B. Tactoid formation in montmorillonite. Journal of Physical Chemistry C 2012, 116, 25425-25433.

(39) Lambe, T. W.; Whitman, R. W. Soil mechanics; Wiley: New York, NY, 1969.

(40) Ben-Naim, E.; Knight, J. B.; Nowak, E. R.; Jaeger, H. M.; Nagel, S. R. Slow relaxation in granular compaction. Physica D 1998, 123, 380-385.

(41) Boutreux, T.; de Gennes, P. G. Compaction of granular mixtures: a free volume model. Physica A 1997, 244, 59-67.

(42) Vandamme, M.; Ulm, F.-J. Nanogranular origin of concrete creep. Proceedings of the National Academy of Sciences of the United States of America 2009, 106, 10552-10557.

(43) Bažant, Z. P.; Hauggaard, A. B.; Baweja, S.; Ulm, F.-J. Microprestress-solidification theory for concrete creep. I: Aging and drying effects. Journal of Engineering Mechanics 1997, 123, 1188-1194.

(44) Bauchy, M.; Masoero, E.; Ulm, F.-J.; Pellenq, R. Creep of bulk C-S-H: Insights from molecular dynamics simulations. 2015; http://arxiv.org/abs/1506.06435.

(45) Leung, C. F.; Lee, F. H.; Yet, N. S. The role of particle breakage in pile creep in sand. Canadian Geotechnical Journal 1996, 33, 888-898. 


\section{${ }_{618}$ Table of Contents Graphic}
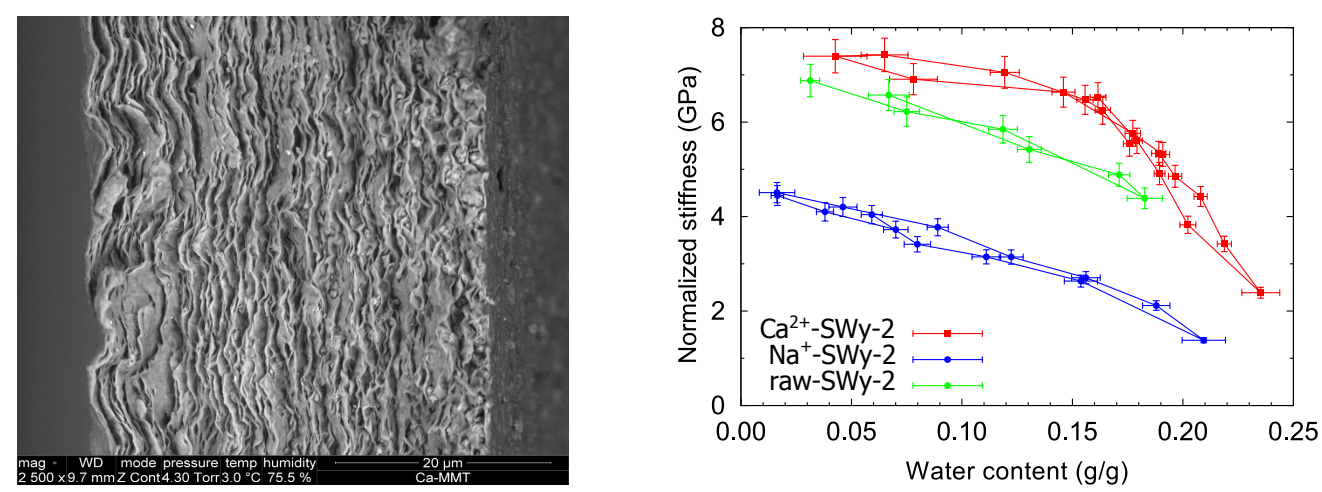